\title{
Furniture Online Consumer Experience: A Literature Review
}

Shuangjie Zhang, Jiangang Zhu,* Guokun Wang, Shuangyue Reng, and Huan Yan

In recent years, people's acceptance of online shopping has increased markedly with the gradual maturing of e-commerce. The furniture industry in China, along with many other countries, is paying increased attention to the online retail business. The furniture online consumption experience has attracted attention both in academic and industrial fields. The purpose of this paper is to provide a literature review of the furniture online consumption with an aim to extend the concept of consumer experience to the context of online furniture consumption. The paper offers three important contributions for both academics and practitioners. First, it analyzes the main influencing factors of the consumer experience concerning wood furniture online consumption in China. And secondly, it proposes a conceptual framework of furniture online consumer experience (FOCE), which divides online consumption experience into three dimensions: perceived risk experience, emotional experience, and new technology interactive experience. Finally, from a managerial perspective, the authors put forward constructive strategies in terms of furniture online sales. The findings of this study afford practical implications for the improvement of the online shopping experience of consumers for furniture companies.

DOI: 10.15376/biores.17.1.1627-1642

Keywords: Furniture consumption; Online shopping; Consumer experience; Interactive experience

Contact information: College of Furnishings and Industrial Design, Nanjing Forestry University, Nanjing 210037, China; *Corresponding author: austin_zhu@njfu.edu.cn

\section{INTRODUCTION}

Since the advent of e-commerce, China's online retail industry has developed rapidly, and consumers have a greater interest in online shopping. The "Internet Plus" policy announced by Chinese government in 2015, encourages people to use network information technology (IT) to promote innovations in e-commerce and online shopping (Xiong et al. 2017). The proportion of furniture companies that choose to sell furniture online is higher than before; as of 2020, the market share of online Chinese brands in the furniture industry has reached more than 80\% (Alibaba Research Institute 2020). According to the China National Bureau of Statistics, the number of furniture markets in China has gradually decreased, from 179 in 2016 to 149 in 2020 (China National Bureau of Statistics). The scale of furniture e-commerce is becoming increasingly larger (Qianzhan Industry Research Institute 2018), from 49.47 billion in 2011 to 165.06 billion in 2017 . The scale of Chinese furniture e-commerce market is shown in Fig. 1. E-commerce in China's furniture industry is mainly based on the business-to-customer (B2C) model. The following three main approaches have emerged in the online retail market under this model. 
The first approach is the furniture brands' self-built electronic mall and selfdeveloped mobile application. In this mode, consumers can complete the transaction by browsing the product information on the website or application, selecting the product and the delivery address, and completing the payment. In the context of sustainability and customers' demand on green consumption, the transition towards green manufacturing of furniture industry increasingly urgent than ever. (Xiong et al. 2020 and Wang et al. 2020). This way makes the process of furniture retailing and purchasing informatized and networked, saves a certain amount of manpower and material costs, and brings consumers a unique and complete consumer experience. But the subsequent development and postmaintenance of the website and application costs also discourage most small businesses, since there is a need for continuous investment in labor and material costs related to networking.

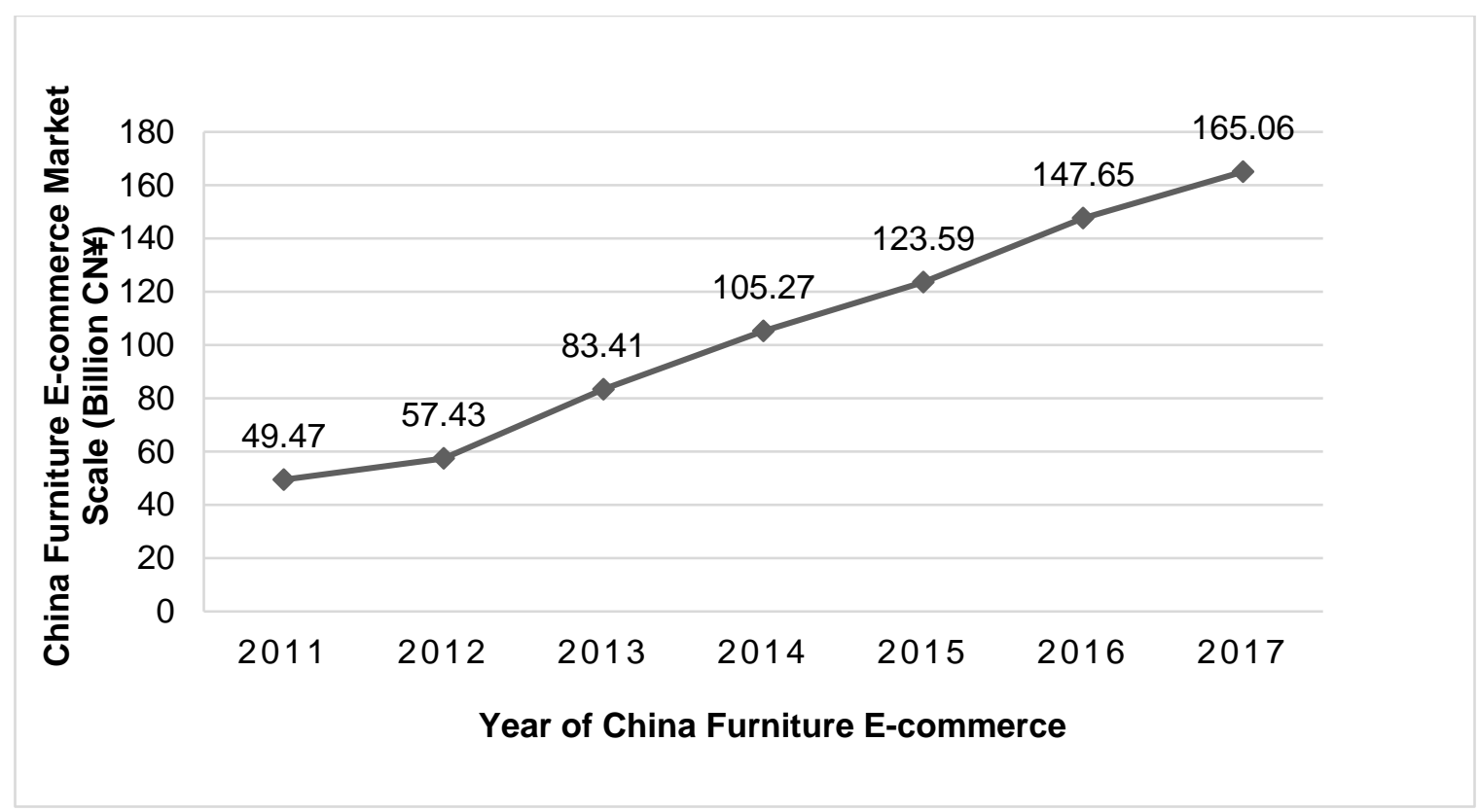

Fig. 1. China Furniture E-Commerce Market Scale

The second approach is to integrate sales on e-commerce platforms such as Taobao and JD.com. Alibaba and JD account for more than 90\% of China's online retail market share (China Internet Information Center 2015). E-commerce platforms provide commodity information a display space and transaction methods for the settled stores. At the same time, the e-commerce platform has gradually standardized the management of furniture stores, which has made the service offering by various furniture brands online stores become more comprehensive and standardized, reducing the psychological risks of consumers buying furniture online. However, it has also caused the service promised by the retailers on the product display page to become more uniform with higher homogeneity.

The third approach is mobile commerce platform sales. With the vigorous development of new media technology, new media platforms, such as Weibo, WeChat Mini Programs, and TikTok, have launched commodity retail functions. In particular, the more intuitive way of displaying goods, such as live broadcast selling, which is an emerging marketing method that uses Internet platforms to introduce and display products to be sold in real time (Liu and Shi 2020). Furniture companies in China are actively 
participating in this new marketing method. According to Xiao and $\mathrm{Yu}$ (2017), although there are various forms of new media, it is found that the most suitable for information spreading in the furniture industry is still graphic, live broadcast, followed by short video.

There have been many studies that have demonstrated the influence of consumer experience on consumer satisfaction and repurchase intentions (George 2002; Rose et al. 2011). In a saturated and highly competitive market, improving the online shopping experience is important for companies to provide more special and differentiated products and services (Rose et al. 2011). The research of Janda and Ybarra (2005) purports that excellent consumer experience has a positive impact on consumer satisfaction. Khalifa and Liu (2007) defined repurchase intention as "using online channels to buy goods from specific retailers". After investigation, it was found that positive online consumer satisfaction is positively correlated with repurchase willingness (Khalifa and Liu 2007). In the context of the fierce competition in the Chinese furniture industry and the highly saturated market, the current article analyzes the components of online consumer experience and their impact and provides some suggestions for furniture companies to optimize customer service.

The aim of this paper is to provide a comprehensive review of contemporary literature that informs our understanding of the antecedents and consequences of consumer experience (CE) in the furniture online consumption context. The review is undertaken in hope of highlighting the importance of this emerging area of interest. This paper expects to carry out several explorations. The first is adding the knowledge of the subject of CE in the furniture online consumption context. The paper extends the understanding of the factors related to online consumer experience from the perspective of the furniture consumption. The second is to propose a theoretical framework for furniture online consumer experience (FOCE) through a summary of the literature on furniture online consumption. Third, the theoretical framework proposed in the thesis puts forward many suggestions to improve furniture online consumption experience for retailers in the Chinese furniture industry.

The structure of the paper is as follows. The first section presents the research method used for this literature review. A literature review of the concept of FOCE is then provided, and the proposed conceptual framework is presented. The following section provides the substantive literature review, structured according to the framework. Finally, the paper ends with a summary of the conclusions that can be drawn from the review and makes proposals for further research.

\section{LITERATURE REVIEW}

\section{Method}

A systematic review of the literature was undertaken using the following method. A review question was identified by the research team: What is the role of consumer experience in the furniture online consumption environment? Then search keywords were drawn up by the team, which included: furniture consumption; furniture industry; furniture online consumption; consumer experience; online consumer experience; interactive experience; and augmented reality. References came from Google Scholar, Web of Science, and China National Knowledge Infrastructure (CNKI).

The articles were screened according to the topics expressed in the title and abstract of the paper. The content analysis of selected papers was done manually, and data 
extraction forms were used to summarize key data, such as key findings and methodological characteristics. This enables researchers to identify the overall nature, epistemological assumptions, and methodological characteristics of existing research. Furthermore, the team created a list to categorize the content of the forms according to the research direction.

This paper focuses on the consumer experience in furniture online purchase environment and the features of furniture consumption in China. Therefore, the authors paid equal attention on the concept of consumer experience, OCE, and furniture retail in China to propose a theoretical framework to systematically answer the review questions mentioned above.

\section{The Concept of FOCE}

There have been many studies on the concept of consumer experience (CE) in the fields of consumer marketing, service delivery, tourism, and retail before the advent of the Internet. With the rapid development of e-commerce, research on retail consumer experience has gradually shifted from offline to online. However, people's attitudes towards the online shopping experience are often related to the types of goods, i.e., people are more likely to perceive the shape and weight of electronic products, and they have a higher tactile demand for clothes (Li et al. 2001). Because of the large volume and price of furniture products, people rely much on consumer experience (Lin et al. 2019) to perceive the spatial and tactile elements of furniture during the consumption process.

Many studies have recognized the importance of CE in the retail market (Grewal et al. 2009). Furniture products are suitable for China's e-commerce platform, as large-scale durable products, under certain conditions ( $\mathrm{Li}$ et al. 2020). However, CE is still an unfamiliar concept for online furniture retail, which is not conducive to the establishment of a theoretical framework. Next in this paper, a certain literature review and summary of the concepts of CE and OCE is given, and the theoretical framework of FOCE is proposed.

\section{Consumer Experience}

Meyer and Schwager (2007) defined consumer experience as the customer's internal and subjective response to any direct or indirect contact with the company. Similarly, Gentile et al. (2007) argued that consumer experience comes from a series of interactions between consumers and services, products, companies, or their organizations. The above literature analyzes the source of consumer experience from the perspective of the consumption process.

In terms of the dimensions of consumer experience, Babin et al. (1994) proposed that consumer experience is composed of utilitarian elements and hedonic elements. They further demonstrated the rational combination of the two elements of the consumer experience under specific circumstances. Berry et al. (2006) made important contributions. According to Berry et al. (2006), consumers often evaluate their consumption experience through functional clues (meeting customer expectations), mechanic clues (influencing first impressions, expectations, and value creation), and humanic clues (exceeding customer expectations) in the process of interacting with organizations. The importance of this classification is to classify the consumer experience as different aspects of the contact between consumers and organizations.

Based on the above literature review, the overall consumer experience can be defined as: customer experience is the internal and subjective reaction of any direct or indirect contact between customers and the company. Direct contact usually occurs during 
purchase, use, and maintenance, a process usually initiated by the customer. The most common way of indirect contact is contact with the company's products, services, or brands, in the form of word-of-mouth recommendations or advertisements, news reports, reviews, etc. The process of generating consumer experience includes the first impression generated by indirect contact, consumer expectations, to functional satisfaction generated by direct contact, and finally the consumer's evaluation of the consumer behavior after using the product and service (whether it meets or exceeds the consumer's expectations).

\section{Online Consumer Experience}

With the rapid development of commerce online, increased attention is being paid to the research of consumers' online experience. Consumer experience in the context of ecommerce is an important factor restricting the development of Chinese furniture ecommerce (Niu and Liu 2017). Therefore, online consumer experience has become an important concept, especially in the context of online shopping. It is believed that the offline context can provide a richer information display method than online. The online environment can only display the brand through an audio-visual way, but a range of visible devices can be used to present the brand in an offline environment.

Long (2004) believes that the online consumer experience is mainly affected by the trustworthiness of the website, convenience, customer autonomy, and the relationship between the website and the customer. Constantinides and Geurts (2005) believe that online consumer experience is related to website interactivity, aesthetics, trust, convenience, and marketing. Although the above authors put forward the factors affecting online consumer experience, these works did not propose a reliable conceptual model of online consumer experience. Frow and Payne (2007) proposed that the rational, cognitive process, and the perceptual and emotional process are all part of the formation of consumer experience. Similarly, Hansen (2005) argued that cognitive and emotional identification, as well as the interaction of these, is an appropriate method to understand consumer experience. With the recent rapid development of the internet, more authors have shifted their research focus from offline to online. Many authors have proposed their own online consumer experience models with reference to the Frow and Payne (2007) model. The table below summarizes some of them.

Table 1. Dimensions of Online Consumer Experience

\begin{tabular}{|c|c|}
\hline Author & Dimensions of Online Consumer Experience \\
\hline Luo (2011) & $\begin{array}{c}\text { Technical experience, information experience, functional } \\
\text { experience, processing experience, and aesthetic experience }\end{array}$ \\
\hline Song (2012) & $\begin{array}{c}\text { Functional experience, brand experience, and emotional } \\
\text { experience }\end{array}$ \\
\hline Bi and Qiu (2014) & $\begin{array}{c}\text { Perception experience, emotional experience, and trust } \\
\text { experience }\end{array}$ \\
\hline Guo and Wang (2013) & $\begin{array}{c}\text { Customer interaction in website, network platform characteristics, } \\
\text { and customer characteristics }\end{array}$ \\
\hline
\end{tabular}

Compared with the offline environment, the online consumer experience places more emphasis on considering the enterprise's application of data and technology to the consumer level, such as convenience, interactivity, process experience, technical experience, etc. (Tan 2019). 


\section{A CONCEPTUAL FRAMEWORK OF FOCE}

Previous reviews of the literature mainly have focused on consumer experience and online consumer experience, while the focus of this article is on the particularity of online consumer experience in furniture consumption. Furniture products have the following characteristics due to their high prices: low standardization, high transportation costs, and many additional services.

The online consumption of furniture has the following characteristics. First, consumers are more cautious when buying furniture products online, hoping to obtain more product information. Online consumers want to check the material, workmanship, style, and shape of furniture in offline physical stores (Cao et al. 2014).

Secondly, delivery restricts online sales of furniture. This is because furniture products have the characteristics of larger size, heavier weight, and relatively higher value. Moreover, furniture e-commerce companies in China are mainly small and medium-sized enterprises. Most of them complete the logistics process through third-party logistics companies or joint distribution. The logistics links are prone to differences in reliability and response. It is difficult for consumers to obtain the fast and convenient logistics services they want (Zhang and Xu 2019).

Finally, spiritual connotation of furniture consumption can bring users a consumption experience similar to luxury goods. It is believed that furniture consumption tends to become symbolic (Dou and Chen 2014). As China enters the consumer society, more consumers are purchasing furniture to show their social status and lifestyle, and furniture consumption is increasingly showing a trend of pursuing spirit demand rather than material demand.

The importance of consumption experience lies in the fact that in a highly competitive and saturated market, enterprises hope to provide differentiated products by enriching basic products and services (Rose et al. 2011). It is useful to understand the dimension of consumption experience from the perspective of the relationship between enterprises and consumers, because the concept of consumption experience comes from this. De Keyser et al. (2015) think that consumers are active participants in the shopping experience, and they pursue cognitive and emotional goals in online and offline shopping (Kawaf and Tagg 2017).

The consumer's cognitive experience is related to the perceived value of consumers. Wang (2008) define the consumer's perceived value as the overall evaluation of the trade-off between the perceived quality of the received product or service and the total cost of obtaining the product or service. Many scholars define perceived value separately as perceived advantage and perceived risk. Forsythe et al. (2006) define perceived advantage as the sum of consumer needs or desires and online shopping advantage or satisfaction. Perceived advantages include advantages related to online shopping experience, including convenience, price comparison, time saving, return policies, shopping convenience, entertainment, and enhanced consumer-retailer relations (Elwalda et al. 2016). With regard to the elements of perceived risk, Wang et al. (2006) pointed out that the quality of products or services, personal privacy, and security are frequent risk elements. The basic concerns of consumers are those of conducting online financial transactions. When the authors discuss online furniture consumption, the boundary between the two concepts does not seem to exist. Online furniture consumption is different from other products; consumers pay more attention to the cognitive experience, such as the shape, size, and quality of the furniture (Dai 2013). These factors are often the 
premise for consumers to determine whether goods are available or not to avoid economic losses and the failure of return services. Therefore, this paper refines the cognitive experience in online furniture consumption into a low-risk experience perceived by consumers.

The emotional experience is more personal and subjective, and shopping experience during shopping relies on entertainment and escapism (De Keyser et al. 2015). These aspects bring more entertainment to customers. Jeong et al. (2009) tested four experience areas (entertainment, educational, escapist, and aesthetic experiences) of Pine and Gilmore (1999) in the online shopping environment. In the online sales of furniture in China, the best-selling of various styles of furniture demonstrates the consumers' demand for the aesthetic experience of furniture. The major e-commerce platforms hold a variety of furniture purchase experience activities every year to meet consumers' demand for shopping and entertainment.

Most previous research divided online consumption experience into cognitive experience and emotional experience. This paper argues that the experience brought by new technology cannot be ignored; the application of high-end technology is the inevitable way to meet the needs of consumers (Chen and Wu 2018). According to the degree of interaction between consumers and goods, Li et al. (2001) divides consumer experience into direct experience, indirect experience, and virtual experience, in which the experience brought to consumers by virtual experience often combines cognitive experience and emotional experience. The virtual fitting technology defined as VTO (virtual try-on) has both use value and hedonic value (Zhang et al. 2019), which means that the virtual experience involves both cognitive and emotional experience. Similarly, another virtual technology defined as AR (augmented reality) has similar characteristics. Poushneh and Vasquez-Parraga (2017) pointed out that AR can reflect four product characteristics: aesthetic quality, pragmatic quality, stimulating hedonistic quality, and identifying hedonistic quality. As augmented reality technology becomes more affordable, many retailers, such as IKEA, have implemented augmented reality in their experiential retail channels. Therefore, this paper takes the new technology interactive experience as the third part of the online furniture consumption experience.

Based on the above literature review on the characteristics of online furniture consumption, this paper proposes the theoretical framework of furniture online consumption experience in Fig. 2 based on the theoretical structure of Frow and Payne (2007). This framework divides the furniture online consumption experience into three parts: perceived low-risk experience, emotional experience, and new technology interactive experience. There are several influencing elements in each experience. 


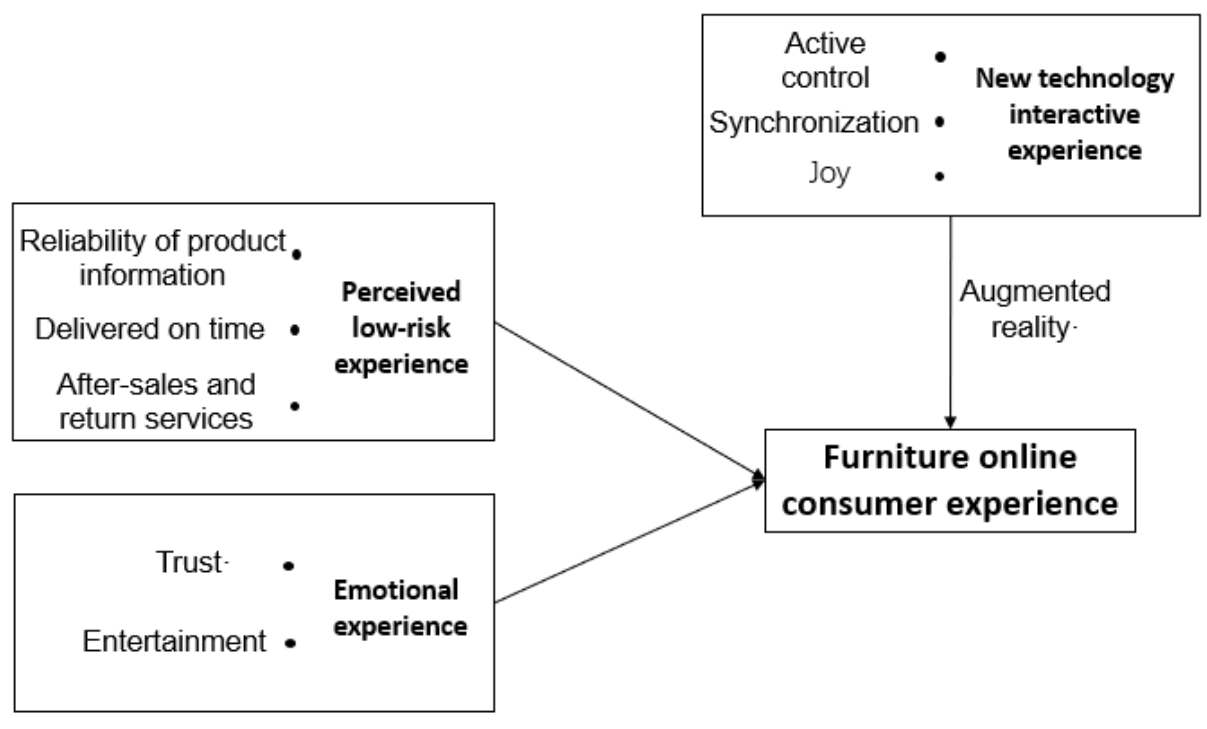

Fig. 2. A conceptual framework of FOCE

\section{DISCUSSION}

\section{Perceived Low-risk Experience}

Bhatnagar et al. (2000) and Lim (2003) put forward the concept of risk perception when shopping online. They believe that it has an important influence on consumers' willingness to interact online. Perceived risk of online shopping is primarily the uncertainty of product information, followed by the severity of the consequences of purchase (Cases 2002). In China, online furniture consumers are mainly concerned about the product inconsistency with the description and quality issues (Li et al. 2016). This paper combines various viewpoints in the literature and divides the perceived risk experience into three aspects: the reliability of product information, logistics and delivery, and after-sales service (repair and return). The reasons for selecting these three factors will be discussed separately below.

When shopping online, the reliability of furniture product information is important, because furniture products have larger size, their materials are highly relevant to people's daily life, and it is important that the product matches the home environment when placed in the domestic environment after purchase. Patro and Katta (2020) found that among perceived risks, the greatest impact on consumers is psychological risk, and an important part of psychological risk is whether the retailer's commitment is consistent with the facts (Zhang et al. 2011). Therefore, for online furniture consumption, the reliability of product information provided by online retailers is crucial.

Another factor that can bring lower perceived risk to consumers is on-time delivery. Delivery has the greatest impact on consumers' perceived benefits online (Patro and Katta 2020), which means that excellent delivery can reduce consumer perceptions risk. On the contrary, any failure or delay in delivery will leave a bad evaluation for online consumers and reduce repurchases (Reichheld and Schefter 2000). Similarly, Rao et al. (2011) identified that the delay in the delivery of goods will reduce the frequency of online purchases by consumers in the future. In other words, online retailers can improve the consumer experience and repurchase rate by promising a shorter delivery time on the website and fulfilling these promises. 
The last factor that affects consumers' perceived risks is the after-sales experience, including returns and installation, maintenance services, etc. Furniture products (such as beds, wardrobes, etc.) often require professionals to complete the installation work. After consumers purchase furniture online, if retailers can provide door-to-door installation services, it will increase consumer satisfaction and repurchase rates (Zhang and Xu 2019). In addition, after purchasing furniture online, if consumers are not satisfied with the product after receiving the goods, they often will not choose to return the goods because of the inconvenience of returning the goods (Dai 2013). This also leads to a bad online consumer experience.

The above discussion of perceived risk experience mainly involves the cognitive part of online consumer experience, and the research of Barari et al. (2020) shows that consumers tend to pursue emotional experience when sufficient cognitive value has been obtained during their consumption experience. Next the emotional experience part of the furniture online consumer experience is discussed.

\section{Emotional Experience}

Emotional experience depends on entertainment and escapism in the shopping process (De Keyser et al. 2015). The emotional experience is personalized and subjective, bringing fun and pleasure to customers (Holbrook and Hirschman 1982). Users' different preferences for furniture products are related to the positive, neutral, or negative state of their emotions (Yang et al. 2019). When people are engaged in entertainment activities, such as the popular online celebrity live broadcasts in China, it is easy for this to become an incentive for consumers to buy goods.

Another factor related to emotional experience is online trust. Many studies have pointed out that due to more unknowns, compared with face-to-face retail, the online environment requires a higher degree of trust (Corbitt et al. 2003; Van der Heijden et al. 2003). Van der Heijden et al. (2003) shows that a high degree of trust can reduce consumers' concerns about product performance and retailer policies.

There have been many academic studies on the source of online trust. Lv et al. (2016) argues that real-time communication between buyers and sellers through online chat services reduces the uncertainty of buyers in making purchasing decisions. Similarly, Mero (2018) proved the positive impact of two-way communication on trust through empirical research.

Perceived interaction is the premise of trust based on interpersonal relationships. Online consumers form online trust in websites through the three aspects of perceptual interaction (perceived interactivity, perceptual reactivity, and perceptual personalization) (Wu et al. 2010). The rise of the internet has brought the need for interactivity in digital media and digital technology researching background. A review of the new contributions of some new interactive technologies to the online consumer experience will be discussed next.

\section{New Technology Interactive Experience}

Liu and Shrum (2002) define interactivity as "the degree to which two or more communicating parties can interact, their role on the communication medium, the role of messages, and the degree to which this influence is synchronized." They also proposed three aspects of interaction: active control (user's ability to voluntarily participate in and influence communication with tools); two-way communication (two-way information flow); and synchronization (the speed of interaction). Chinese customers' cognitions 
around products have changed from store + facade to reality $+\mathrm{VR}$, which gives consumers a different experience via VR (Xiong et al. 2017). Traditional product information acquisition is often passive and single (only through sound and video acquisition), but the augmented reality technology that has gradually attracted the attention of academia recently seems to be suitable for online sales: shopping in the context of enhanced interactive technology can arouse consumers' greater purchase intentions than passively accepting product information display (Kim and Forsythe 2008).

To understand more concretely, the current authors will use AR as an example to describe the innovation of new technologies in online consumer experience. Poushneh and Vasquez-Parraga (2017) proposed that AR is an interactive technology that can overlay virtual 3D models into the real environment. Users can rotate, move, and zoom in and out in the 3D model to change its state in the real environment.

On the one hand, AR does have some similarities with the risk perception experience and emotional experience. In terms of risk perception experience, the virtual try-on application can provide clues about the physical properties of the product to help consumers evaluate the product more completely (Dennis et al. 2010). Some previous studies have found evidence that virtual try-on may reduce the likelihood that consumers may perceive clothes purchased online as ill-fitting (Shim and Lee 2011; Kim 2016). In terms of emotional experience, Watson et al. (2020) argue that AR seems to provide a happier experience rather than a utilitarian experience. It is also believed that AR creates a rich sensory experience and thus closer emotional responses. Both those with strong or weak hedonistic motives can have fun from AR shopping applications, and those with strong hedonistic motives are more obvious.

In contrast, AR technology seems to explore some new forms of experience, and virtual try-on applications can further enhance the shopping experience. Users can share the results of fittings with friends and family easily (Dennis et al. 2010). Therefore, it can become a social channel, especially when combined with social media applications, to provide online consumers a pleasant shopping experience by meeting their social needs.

In the furniture industry, the furniture brand IKEA has developed the AR application IKEA Place, which can automatically scan the floor in the scene through the mobile phone camera and place the desired product model in the real scene captured by the camera, effectively enhancing the reality sense. The goods added to the scene can be directly clicked to view the product information and purchase, which greatly reduces the process of collecting information, evaluating purchase risks, purchasing and installing, and evaluating purchase results in the consumer process. It brings consumers a new and fast experience. When using the IKEA Place application, users will feel greater confidence and greater purchasing convenience (Alves and Luís Reis 2020).

\section{CONCLUSIONS}

1. A review of key literature is presented with an aim to give insight and direction to an understanding of the online furniture purchases and online consumption experience in China. The three main influencing factors of the consumer experience on Chinese furniture product line can be drawn: (1) Consumers hope to access more furniture information such as materials, style, and size before buying furniture; (2) Consumers want to get a better delivery service and after-sales return service; and (3) Consumers have gradually enhanced demand for entertaining furniture products. This paper 
addresses the adaptability of the online consumer experience model in the Chinese furniture industry by expanding the theoretical structure of Frow and Payne (2007).

2. A conceptual model of furniture online customer experience (FOCE) has been proposed in this work. According to FOCE, the furniture online consumer experience can be divided into three parts: (1) perceived low-risk experience, (2) emotional experience, and (3) new technology interactive experience. In the context of the fastgrowing Chinese furniture e-commerce market, consumers have a strong demand for new consumer experiences. The new technology interactive experience is considered as a new consumption experience type due to its scarcity in online consumption experience in research, although the new technologies interactive experience often combines a perceived experience and emotional experience, and these are often difficult to segment.

3. Furniture companies in China should take solid measures in online product display, size customization, logistics, door-to-door installation, after-sales, and other online value-added services. The offline store appointment experiences also are helpful to minimize consumers' psychological expectations of risks associated with online shopping. Furthermore, surveying consumers' furniture style preferences and organizing brand-related entertainment activities can be more conducive to meeting consumers' emotional needs. Finally, the new technologies, such as AR, have revolutionary advantages in improving the high-level experience brought by the existing services and brands of e-commerce platforms. Furniture companies in China should therefore pay more attention to improvement of the user consumption experience brought by related new technologies.

4. This article has attempted to discuss the essence of consumer experience in furniture online consumption by proposing a theoretical framework. There is no denying that the proposed framework is only conceptual; thus, subsequent development and empirical tests are required to establish more systemic understanding.

\section{ACKNOWLEDGMENTS}

The authors are grateful the support of the Joint Research program of Nanjing Forestry University, Jiangsu Co-Innovation Center of Efficient Processing and Utilization of Forest Resources, and Sino-foreign Cooperation in Running Schools of Jiangsu Province, Jiangsu, China.

\section{REFERENCES CITED}

Alibaba Research Institute (2020). "2020 China consumer brand development report," (https://file.01 caijing.com/attachment/202005/1215D966F6CC4F3.pdf), Accessed 31 May 2020. 
Alves, C., and Luís Reis, J. (2020). "The intention to use e-commerce using augmented reality - The case of IKEA Place," in: Information Technology and Systems. ICITS 2020. Advances in Intelligent Systems and Computing (Vol. 1137), Á. Rocha, C. Ferrás, C. Montenegro Marin, and V. Medina García (eds.), Springer, Cham, Switzerland, pp. 114-123. DOI: 10.1007/978-3-030-40690-5_12

Babin, B. J., Darden, W. R., and Griffin, M. (1994). "Work and/or fun: Measuring hedonic and utilitarian shopping value," Journal of Consumer Research 20(4), 644656. DOI: $10.1086 / 209376$

Barari, M., Ross, M., and Surachartkumtonkun, J. (2020). "Negative and positive customer shopping experience in an online context," Journal of Retailing and Consumer Services 53(1), Article ID 101985. DOI: 10.1016/j.jretconser.2019.101985

Berry, L. L., Wall, E. A., and Carbone, L. P. (2006). "Service clues and customer assessment of the service experience: Lessons from marketing," Academy of Management Perspectives 20(2), 43-57. DOI: 10.5465/amp.2006.20591004

Bhatnagar, A., Misra, S., and Rao, R. (2000). "On risk, convenience, and internet shopping behaviour," Communications of the ACM 43(11), 98-105. DOI: $10.1145 / 353360.353371$

Bi, D., and Qiu, C. (2014). "Research on the influence mechanism of e-commerce business-customer interaction on customer experience," China Software Science 2014(12), 124-135. DOI: 10.3969/j.issn.1002-9753.2014.12.012

Cao, Y., Wu, Z., Yang, B., Li, X., and Li, X. (2014). "Research of status quo and promotion programs of Hongmu furniture e-commerce," Furniture 35(5), 8-14. DOI: 10.16610/j.cnki.jiaju.2014.05.014

Cases, A. (2002). "Perceived risk and risk-reduction strategies in internet shopping," International Review of Retail Distribution and Consumer Research 12(4), 375-394. DOI: 10.1080/09593960210151162

Chen, Y., and Wu, Z. (2018). "Study on the application of particle swarm optimization in the virtual reality of the modified wood furniture," Journal of Intelligent and Fuzzy Systems 35(3), 2741-2747. DOI: 10.3233/JIFS-169626

China National Bureau of Statistics(2021). "The number of China's furniture market in the past five years," (https://data.stats.gov.cn/easyquery.htm?cn= C01\&zb=A0I0901\&sj=2020), Accessed 19 December 2021.

Constantinides, E., and Geurts, P. (2005). "The impacts of web experience on virtual buying behavior: An empirical study," Journal of Customer Behavior 4(3), 307-336. DOI: 10.1362/147539205775181249

Corbitt, B. J., Thanasankit, T., and Yi, H. (2003). "Trust and e-commerce: A study of consumer perceptions," Electronic Commerce Research and Applications 2(3), 203215. DOI: $10.1016 / \mathrm{S} 1567-4223(03) 00024-3$

Dai, L. (2013). "The present and the future of the electronic commerce of Chinese furniture industry," Furniture 34(1), 68-78. DOI: 10.16610/j.cnki.jiaju.2013.01.007

De Keyser, A., Lemon, K. N., Klaus, P., and Keiningham, T. L. (2015). A Framework for Understanding and Managing the Customer Experience (Report No. 15-121), Marketing Science Institute, Cambridge, MA, USA.

Dennis, C., Morgan, A., Wright, L. T., and Jayawardhena, C. (2010). "The influences of social e-shopping in enhancing young women's online shopping behaviour," Journal of Customer Behaviour 9(2), 151-174. DOI: 10.1362/147539210X511353

Dou, L., and Chen, Y. (2014). "Review on Chinese furniture's symbolic consumer behavior," Furniture and Interior Design 2014(1), 82-83. DOI: 10.16771/j.cnki.cn43- 
$1247 /$ ts. 2014.01.029

Elwalda, A., Lü, K., and Ali, M. (2016). "Perceived derived attributes of online consumer reviews," Computers in Human Behavior 56, 306-319. DOI:

10.1016/j.chb.2015.11.051

Forsythe, S., Liu, C., Shannon, D., and Gardner, L. C. (2006). "Development of a scale to measure the perceived benefits and risks of online shopping," Journal of Interactive Marketing 20(2), 55-75. DOI: 10.1002/dir.20061

Frow, P., and Payne, A. (2007). "Towards the 'perfect' customer experience," Journal of Brand Management 15(2), 89-101. DOI: 10.1057/palgrave.bm.2550120

Gentile, C., Spiller, N., and Noci, G. (2007). "How to sustain the customer experience: An overview of experience components that co-create value with the customer," European Management Journal 25(5), 395-410. DOI: 10.1016/j.emj.2007.08.005

George, J. F. (2002). "Influences on the intent to make internet purchases," Internet Research 12(2), 165-180. DOI: 10.1108/10662240210422521

Grewal, D., Levy, M., and Kumar, V. (2009). "Customer experience management in retailing: An organizing framework," Journal of Retailing 85(1), 1-14. DOI: 10.1016/j.jretai.2009.01.001

Guo, H., and Wang, J. (2013). "The study of B2C customer experience model based on Tam model," Science and Technology Management Research 33(19)184-188. DOI: 10.3969/j.issn.1000-7695.2013.19.042

Hansen, T. (2005). "Perspectives on consumer decision-making: An integrated approach," Journal of Consumer Behaviour 4(6), 420-437. DOI: 10.1002/cb.33

Holbrook, M. B., and Hirschman, E. C. (1982). "The experiential aspects of consumption: Consumer fantasies, feelings, and fun," Journal of Consumer Research 9(2), 132-140. DOI: 10.1086/208906

Janda, S., and Ybarra, A. (2005). "Do product and consumer characteristics affect the relationship between online experience and customer satisfaction?," Journal of Internet Commerce 4(4), 133-151. DOI: 10.1300/J179v04n04_09

Jeong, S. W., Fiore, A. M., Niehm, L. S., and Lorenz, F. O. (2009). "The role of experiential value in online shopping: The impacts of product presentation on consumer responses towards an apparel web site," Internet Research 19(1), 105-124. DOI: $10.1108 / 10662240910927858$

Long, K. (2004). “Customer loyalty and experience design in e-business,” Design Management Review 22(16), 60-67. DOI: 10.1111/j.1948-7169.2004.tb00163.x

Kawaf, F., and Tagg, S. (2017). "The construction of online shopping experience: A repertory grid approach," Computers in Human Behavior 72, 222-232. DOI: 10.1016/j.chb.2017.02.055

Khalifa, M., and Liu, V. (2007). "Online consumer retention: Contingent effects of online shopping habit and online shopping experience," European Journal of Information Systems 16(6), 780-792. DOI: 10.1057/palgrave.ejis.3000711

Kim, D. (2016). "Psychophysical testing of garment size variation using threedimensional virtual try-on technology," Textile Research Journal 86(4), 365-379. DOI: $10.1177 / 0040517515591782$

Kim, J., and Forsythe, S. (2008). "Adoption of virtual try-on technology for online apparel shopping," Journal of Interactive Marketing 22(2), 45-59. DOI: 10.1002/dir.20113

Li, H., Daugherty, T., and Biocca, T. (2001). "Characteristics of virtual experience in electronic commerce: A protocol analysis," Journal of Interactive Marketing 15(3), 
13-30. DOI: 10.1002/dir.1013

Li, Y, Gong, M., Li, X., and Zhao, S. (2016). "Research on the Development Strategy of Electronic Commerce of Furniture - The comparative analysis of the furniture buying of entity shop and online shop," Issues of Forestry Economics 36(03), 268-275 DOI:10.16832/j.cnki.1005-9709.2016.03.014

Li, Y., Li, X., Zhang, Z., Zhang, G., and Gong, M. (2020). "Understanding consumers online furniture purchase behavior: An updated UTAUT perspective," Journal of Forest Economics 35(4), 267-303. DOI: 10.1561/112.00000516

Lim, N. (2003). “Consumers' perceived risk: Sources versus consequences," Electronic Commerce Research and Applications 2(3), 216-228. DOI: 10.1016/s15674223(03)00025-5

Lin, M., Wang, Z., Zhang, Z., and Cao, Y. (2019). "Research on consumers' attitudes in china about using online-to-offline mode for purchasing wooden furniture," Forest Products Journal 69(2), 159-172. DOI: 10.13073/FPJ-D-18-00039

Liu, P., and Shi, Y. (2020). "Research on the influencing mechanism of live broadcasting marketing pattern on consumers' purchase decision," China Business and Market (10), 38-47. DOI:10.14089/j.cnki.cn11-3664/f.2020.10.004.

Liu, Y., and Shrum, L. J. (2002). "What is interactivity and is it always such a good thing? Implications of definition, person, and situation for the influence of interactivity on advertising effectiveness," Journal of Advertising 31(4), 53-64. DOI: 10.1080/00913367.2002.10673685

Luo, G. (2011). "Comprehensive evaluation of B2C E-commerce website service quality based on user experience," Market Modernization 2011(1), 100-102. DOI: 10.3969/j.issn.1006-3102.2011.01.063

Mero, J. (2018). "The effects of two-way communication and chat service usage on consumer attitudes in the e-commerce retailing sector," Electronic Markets 28(2), 205-217. DOI: 10.1007/s12525-017-0281-2

Meyer, C., and Schwager, A. (2007). "Understanding customer experience," Harvard Business Review 85(2), 116-126.

Niu, Q., and Liu, H. (2017). "Research progress of e-commerce in furniture industry," Issues of Forestry Economics 37(01), 68-73+108. DOI: 10.16832/j.cnki.10059709.2017.01.012.

Patro, C. S., and Katta, R. M. R. (2020). “Consumers' perceived value in internet shopping: An empirical study," International Journal of Customer Relationship Marketing and Management 11(2), 17-36. DOI: 10.4018/IJCRMM.2020040102

Poushneh, A., and Vasquez-Parraga, A. Z. (2017). "Discernible impact of augmented reality on retail customer's experience, satisfaction and willingness to buy," Journal and Consumer Services 34, 229-234. DOI: 10.1016/j.jretconser.2016.10.005

Qianzhan Industry Research Institute (2018). "Report of forward and investment strategic planning analysis on China furniture manufacturing industry," (https://bg.qianzhan.com/report/detail/459/181129-adfe1b7d.html), Accessed 23 May 2021.

Rao, S., Griffis, S. E., and Goldsby, T. J. (2011). "Failure to deliver? Linking online order fulfillment glitches with future purchase behavior," Journal of Operations Management 29(7-8), 692-703. DOI: 10.1016/j.jom.2011.04.001

Reichheld, F. F., and Schefter, P. (2000). "E-loyalty: Your secret weapon on the web," Harvard Business Review 78(4), 105-113.

Rose, S., Hair, N., and Clark, M. (2011). “Online customer experience: A review of the 
business-to-consumer online purchase context," International Journal of Management Reviews 13(1), 24-39. DOI: 10.1111/j.1468-2370.2010.00280.x

Shim, S. I., and Lee, Y. (2011). "Consumer's perceived risk reduction by 3D virtual model," International Journal of Retail \& Distribution Management 39(12), 945-959. DOI: $10.1108 / 09590551111183326$

Song, W. (2012). A Study of Customer Experience's Effect on Customer Loyalty of B2C Electronic Commerce, Master's Thesis, Shandong University, Shandong, China.

Tan, H. (2019). Research on the Influence of E-commerce Offline Store Experience on Consumers' Online Purchase Intention, Master's Thesis, Chongqing University of Posts and Telecommunications, Chongqing, China.

Van der Heijden, H., Verhagen, T., and Creemers, M. (2003). "Understanding online purchase intentions: Contributions from technology and trust perspectives," European Journal of Information Systems 12(1), 41-48. DOI: 10.1057/palgrave.ejis.3000445

Wang, G., Zhu, J., Cai, W., Liu, B., Tian, Y., and Meng, F. (2021). "Research on packaging optimization in customized panel furniture enterprises," Bioresources, 16(1), 1186-1206. DOI: 10.15376/biores.16.1.1186-1206

Wang, J., Ashleigh, M., and Meyer, E. (2006). "Knowledge sharing and team trustworthiness: It's all about social ties!," Knowledge Management Research \& Practice 4(3), 175-186. DOI: 10.1057/palgrave.kmrp.8500098

Wang, Y. (2008). "Assessing e-commerce systems success: A respecification and validation of the DeLone and McLean model of IS success," Information Systems Journal 18(5), 529-557. DOI: 10.1111/j.1365-2575.2007.00268.x

Watson, A., Alexander, B., and Salavati, L. (2018). "The impact of experiential augmented reality applications on fashion purchase intention," International Journal of Retail \& Distribution Management 48(5), 433-451. DOI: 10.1108/IJRDM-062017-0117

$\mathrm{Wu}, \mathrm{G} ., \mathrm{Hu}, \mathrm{X}$., and Wu, Y. (2010). "Effects of perceived interactivity, perceived web assurance and disposition to trust on initial online trust," Journal of ComputerMediated Communication 16(1), 1-26. DOI: 10.1111/j.1083-6101.2010.01528.x

Xiao, C., and Yu, S. (2017). "Status survey of furniture information dissemination in new medium enviroment," Furniture 38(3), 13-16, +49. DOI:

10.16610/j.cnki.jiaju.2017.03.003

Xiong, X., Guo, W., Fang, L., Zhang, M., Wu, Z., Lu, R., and Miyakoshi, T. (2017). "Current state and development trend of Chinese furniture industry," Journal of Wood Science 63(5), 433-444. DOI: 10.1007/s10086-017-1643-2

Xiong, X., Ma, Q., Yuan, Y, Wu, Z., and Zhang, M. (2020). "Current situation and key

manufacturing considerations of green furniture in China: A review," Journal of Cleaner Production, DOI:10.1016/j.jclepro.2020.121957.

Yang, Y., Liu, W., and Li, G. (2019). "Research on users'cognition of different preferences based on ERPs," Journal of Forestry Engineering 4(05), 152-158. DOI:10.13360/j.issn.2096-1359.2019.05.022

Zhang, L., Tan, W., Xu, Y., and Tan, G. (2011). "Dimensions of perceived risk and their influence on consumers' purchasing behavior in the overall process of B2C," Engineering Education and Management 111, 1-10. DOI: 10.1007/978-3-642-24823-8_1

Zhang, T., Wang, W. Y. C., Cao, L., and Wang, Y. (2019). "The role of virtual try-on technology in online purchase decision from consumers' aspect," Internet Research 29(3), 529-551. DOI: 10.1108/IntR-12-2017-0540 
Zhang, Z., and Xu, B. (2019). "Research on e-commerce logistics service quality problem based on electronic word-of-mouth data mining," China Business and Market 2019(1), 43-55. DOI: 10.14089/j.cnki.cn11-3664/f.2019.01.005

Article submitted: August 16, 2021; Peer review completed: November 14, 2021;

Revised version received and accepted: January 3, 2022; Published: January 18, 2022.

DOI: $10.15376 /$ biores.17.1.1627-1642 